\title{
GAMBARAN PENGETAHUAN TENAGA KESEHATAN TENTANG ANTENATAL CARE DI PUSKESMAS RANOMUUT KOTA MANADO
}

\author{
${ }^{1}$ Dewik A.A. \\ ${ }^{2}$ Henry Palandeng \\ ${ }^{2}$ Ronald Ottay
}

\author{
${ }^{1}$ Kandidat Skripsi Fakultas Kedokteran Universitas Sam Ratulangi Manado \\ ${ }^{2}$ Bagian Ikatan Kedokteran Komunitas Universitas Sam Ratulangi Manado \\ Email: Aini_dewik@yahoo.com
}

\begin{abstract}
Antenatal care is an examination conducted to prevent complications during pregnancy. Antenatal examination is very important during pregnancy, so that health professionals should have knowledge of antenatal care to improve maternal and child health. The aim of this descriptive study is to determine the knowledge of health workers about antenatal care at Ranomuut Health Centers in Manado City. Population in this research that all health professionals who work in the health center Ranomuut totaling 38 people. The number of respondents that health workers who know about antenatal care as many as 25 people. Data were collected through questionnaires. The results showed 25 respondents, all health care workers have had knowledge of antenatal care.
\end{abstract}

Keywords: health workers, antenatal care, knowledge.

\begin{abstract}
Abstrak: Antenatal care merupakan pemeriksaan yang dilakukan untuk mencegah adanya komplikasi selama kehamilan. Pemeriksaan Antenatal sangat penting dilakukan selama masa kehamilan sehingga diharapkan tenaga kesehatan harus memiliki pengetahuan terhadap antenatal care sebagai upaya meningkatkan kesehatan ibu dan anak. Penelitian ini bertujuan untuk mengetahui pengetahuan tenaga kesehatan terhadap antenatal care di Puskesmas Ranomuut Kota Manado. Penelitian ini bersifat deskriptif. Populasi dalam penelitian ini yaitu seluruh tenaga kesehatan yang bekerja di Puskesmas Ranomuut yang berjumlah 38 orang. Jumlah responden yaitu tenaga kesehatan yang mengerti tentang antenatal care sebanyak 25 orang. Data penelitian dikumpulkan melalui kuesioner. Hasil penelitian menunjukkan dari 25 responden, semua petugas kesehatan telah memiliki pengetahuan tentang antenatal care.
\end{abstract}

Kata kunci: tenaga kesehatan, antenatal care, pengetahuan.

Pembangunan kesehatan merupakan bagian dari pembangunan nasional yang bertujuan meningkatkan kesadaran, kemauan, dan kemampuan hidup sehat bagi setiap orang agar terwujud derajat kesehatan masyarakat yang setinggi-tingginya. ${ }^{1,2}$

Kesehatan ibu merupakan masalah nasional yang perlu mendapat prioritas utama, karena sangat menentukan kualitas sumber daya manusia pada generasi mendatang. Ini didasarkan pada tujuan dari Survei Demografi Kesehatan Indonesia
(SDKI), yaitu mengukur pencapaian sasaran dari program kesehatan nasional, khususnya yang berkaitan dengan program pembangunan kesehatan ibu dan anak (KIA). ${ }^{3,4}$

Menurut SDKI tahun 2007, Angka Kematian Ibu (AKI) di Indonesia mencapai 248/100.000 kelahiran hidup. Jadi setiap 100.000 kelahiran hidup, sekitar 248 ibu meninggal akibat komplikasi kehamilan dan persalinan. ${ }^{4}$

Angka Kematian Ibu di Indonesia pada tahun 2011 sebanyak 228/100.000 kelahiran 
hidup, sedangkan di Provinsi Sulawesi Utara tercatat 186 kasus per 100.000 penduduk. Target yang ditetapkan oleh Millenium Development Goals (MDGs), bahwa pada tahun 2015 AKI sebanyak 102 kasus per 100.000 penduduk, maka AKI di Sulawesi Utara masih tergolong tinggi.,

Demi mencapai tujuan MDGs dapat dilakukan strategi dengan pendekatan secara individual, yaitu pada saat ibu datang ke fasilitas pelayanan kesehatan untuk memeriksaan kehamilannya (antenatal care). Salah satu faktor yang berpengaruh terhadap tingginya AKI yaitu ketidakpatuhan ibu terhadap kunjungan antenatal. ${ }^{6,7}$

Kehamilan resiko tinggi merupakan faktor utama tingginya AKI di seluruh dunia. Pemeriksaan kehamilan yang baik dan tersedianya fasilitas rujukan bagi kasus resiko tinggi dapat menurunkan angka kematian ibu. ${ }^{8,9}$ Namun kualitas pelayanan kesehatan menjadi salah satu faktor rendahnya cakupan kunjungan antenatal. ${ }^{10}$

Pada tahun 1980-an, pusat pelayanan kesehatan begitu ramai dikunjungi pasien yang hendak berobat, namun fenomena itu kini jarang terjadi. Sebagai pusat pelayanan kesehatan masyarakat, puskesmas harusnya dapat menjadi tempat rujukan pertama dengan pelayanan prima yang dapat menampung berbagai masalah kesehatan yang terjadi pada masyarakat. Selain itu hal yang lebih fatal lagi yakni petugas puskesmas tidak begitu tanggap dengan pelayanan medik, namun lebih menekankan biaya administrasi. $^{10}$

Seorang tenaga kesehatan khususnya bidan harus memiliki pengetahuan yang luas, memiliki motivasi yang tinggi, dituntut untuk menggunakan kemampuan dalam berbagai aspek kehidupan khususnya dalam memberikan pelayanan kepada pasien, sehingga dengan demikian dapat memberikan dampak yang positif sesuai dengan bidang ilmu yang dimilikinya. Tetapi pelaksanaan pelayanan antenatal menemui sejumlah hambatan, yang disebabkan kurang pengetahuan bidan tentang pelayanan antenatal. Secara teoretis, tindakan yang diberikan oleh tenaga kesehatan (bidan) pada saat pemeriksaan kehamilan akan sangat banyak berpengaruh terhadap kesehatan ibu dan janin yang dikandungnya karena di pemeriksaan yang lengkap akan mudah mendeteksi kelainan-kelainan yang mungkin terjadi pada saat kehamilan atau menjelang kelahiran. ${ }^{11}$

Berdasarkan data yang diperoleh di atas, peneliti menganggap perlu melakukan penelitian tentang pengetahuan tenaga kesehatan terhadap antenatal care di Puskesmas Ranomuut Kota Manado.

\section{METODOLOGI}

Penelitian ini bersifat deskriptif dengan menggunakan metode survey. Penelitian dilakukan di Puskesmas Ranomuut pada bulan November 2012-Januari 2013. Populasi pada penelitian ini yaitu seluruh tenaga kesehatan yang bekerja di Puskesmas Ranomuut yang berjumlah 38 orang dan yang menjadi sampel yaitu tenaga kesehatan yang mengerti tentang antenatal care yang berjumlah 25 orang, terdiri dari 6 dokter, 5 bidan dan 14 perawat. Karakteristik Responden yaitu umur, tingkat pengetahuan dan pengetahuan tenaga kesehatan tentang ANC. Data diperoleh melalui pengisian kuesioner oleh tenaga kesehatan yang bekerja di Puskesmas Ranomuut. Pengolahan data dilakukan secara manual menggunakan komputer dan disajikan dalam bentuk Tabel.

\section{HASIL PENELITIAN}

Berdasarkan hasil penelitian yang dilakukan terhadap tenaga kesehatan di Puskesmas Ranomuut periode November 2012-Januari 2013 diperoleh data yang disajikan dalam bentuk tabel distribusi sebagai berikut:

\section{Karakteristik Responden}

Tabel 1. Distribusi responden berdasarkan umur

\begin{tabular}{lcc}
\hline Umur & $\mathbf{N}$ & $\mathbf{\%}$ \\
\hline $20-30$ & 5 & 20 \\
$31-40$ & 11 & 44 \\
$41-50$ & 5 & 20 \\
$>50$ & 4 & 16 \\
\hline Jumlah & $\mathbf{2 5}$ & $\mathbf{1 0 0}$ \\
\hline
\end{tabular}


Berdasarkan Tabel 1 dapat dilihat bahwa distribusi umur responden yang terbanyak berkisar antara umur 31-40 tahun yaitu sebanyak 11 responden (44\%).

Tabel 2. Distribusi responden berdasarkan pendidikan terakhir

\begin{tabular}{ccc}
\hline Pendidikan Terakhir & $\mathbf{N}$ & $\mathbf{\%}$ \\
\hline SPK & 12 & 48 \\
D3 & 2 & 8 \\
S1 & 11 & 44 \\
\hline Jumlah & $\mathbf{2 5}$ & $\mathbf{1 0 0}$ \\
\hline
\end{tabular}

Berdasarkan Tabel 2 dapat dilihat bahwa distribusi responden yang terbanyak berdasarkan pendidikan terakhir adalah SPK yaitu sebanyak 12 responden (48\%).

\section{Pengetahuan tenaga kesehatan tentang definisi ANC, tujuan ANC, pelaksanaan ANC dan pemantauan kehamilan.}

Distribusi responden yang terbanyak berdasarkan tenaga kesehatan yang mengetahui definisi ANC menjawab pemeriksaan dan pengawasan selama kehamilan yaitu sebanyak 25 responden (100\%).

Distribusi responden yang terbanyak berdasarkan tenaga kesehatan yang mengetahui tujuan ANC yaitu menjawab mendapatkan ibu dan anak yang sehat setelah persalinan sebanyak 25 responden (100\%).

Distribusi responden yang terbanyak berdasarkan tenaga kesehatan yang melakukan pemeriksaan kehamilan yaitu menjawab bidan dan dokter sebanyak 25 responden (100\%).

Distribusi responden yang terbanyak berdasarkan pemeriksaan kehamilan yang biasa dilakukan yaitu sebanyak 25 responden (100\%) menjawab belum memenuhi kriteria 7T yaitu; timbang berat badan, ukur tekanan darah, ukur tinggi fundus uteri, pemberian imunisasi TT (Tetanus Toksoid Lengkap), pemberian tablet besi, tes terhadap penyakit menular seksual dan temu wicara dalam rangka persiapan rujukan.
Distribusi responden yang terbanyak berdasarkan jadwal kunjungan ANC menjawab satu kali pada trimester I dan II, dua kali pada trimester III yaitu sebanyak 25 responden (100\%).

Distribusi responden yang terbanyak berdasarkan pemberian buku KIA menjawab YA yaitu sebanyak 25 responden (100\%).

Distribusi responden yang terbanyak berdasarkan manfaat buku KIA menjawab berisi informasi yang berguna untuk kesehatan ibu dan anak serta untuk tenaga kesehatan yaitu sebanyak 25 responden $(100 \%)$.

\section{BAHASAN}

\section{Karakteristik Responden}

Berdasarkan Tabel 1 dapat dilihat bahwa distribusi umur responden yang terbanyak berkisar antara umur 31-40 tahun yaitu sebanyak 11 responden (44\%). Hal ini sesuai dengan penelitian yang dilakukan oleh Dhesi (2008) yang menunjukkan bahwa berdasarkan umur, semua responden termasuk dalam umur $>30$ tahun. Umur responden yang tergolong tua memberikan gambaran bahwa responden telah memiliki pengalaman yang cukup. Pengalaman responden membentuk perilaku yang akan menjadi kebiasaan. ${ }^{11}$ Menurut Hasan (2002) umur terkait dengan kedewasaan berpikir seseorang. Keputusan yang dihasilkan seseorang yang dewasa bersifat lebih objektif dan menggunakan logika sehingga dapat mendekati kebenaran atau sesuai yang diinginkan. ${ }^{11}$

Berdasarkan Tabel 2 dapat dilihat bahwa distribusi responden yang terbanyak berdasarkan pendidikan terakhir adalah SPK yaitu sebanyak 12 responden (48\%). Hal ini tidak sesuai dengan penelitian yang dilakukan Dhesi (2008), dimana dalam penelitiannya responden berdasarkan tingkat pendidikan terbanyak yaitu D3 sebanyak 18 orang (75\%). Dalam penelitiannya, pengetahuan responden dengan pendidikan D3 mempunyai kelebihan dari sisi kemampuan dan pengalaman dalam praktek kebidanan atau asuhan antenatal. Sedangkan pengetahuan responden dengan pendidikan 
dibawah D3 tentang asuhan antenatal masih kurang sebab materi yang diberikan masih terbatas oleh waktu sehingga akan membatasi pengetahuan yang dimilikinya. ${ }^{11}$

\section{Pengetahuan tenaga kesehatan terhadap definisi ANC, tujuan ANC, pelaksanaan ANC, pemantauan kehamilan}

Distribusi responden yang terbanyak berdasarkan tenaga kesehatan yang mengetahui definisi ANC menjawab pemeriksaan dan pengawasan selama kehamilan yaitu sebanyak 25 responden (100\%). Seorang tenaga kesehatan terutama bidan dan dokter harus mengetahui pemeriksaan dan pengawasan selama kehamilan yang biasa dikenal dengan antenatal care agar dapat menjalankan perannya secara optimal yaitu meningkatkan kesehatan ibu dan anak, dan tenaga kesehatan khususnya bidan, wajib memiliki pengetahuan yang luas, memiliki motivasi yang tinggi, dan dituntut untuk menggunakan kemampuan dalam berbagai aspek kehidupan khususnya dalam memberikan pelayanan kepada pasien. Dengan demikian dapat memberikan dampak yang positif sesuai dengan bidang ilmu yang dimilikinya. $^{12}$

Distribusi responden yang terbanyak berdasarkan tenaga kesehatan yang mengetahui tujuan ANC yaitu sebanyak 25 responden (100\%) menjawab mendapatkan ibu dan anak yang sehat setelah persalinan. Setelah mengetahui tentang pemeriksaan dan pengawasan selama kehamilan, tenaga kesehatan harus mengetahui juga tujuan antenatal care. Pelayanan antenatal sendiri berguna untuk mencegah masalah kesehatan pada ibu dan bayi serta melihat bahwa setiap anak yang baru lahir memiliki awal yang baik, dimana perawatan yang diberikan juga harus tepat dan tidak berlebihan. Teknologi baru juga perlu dilaksanakan secara terus menerus, sementara layanan yang lebih tua perlu dipertimbangkan kembali dan perawatan untuk setiap wanita hamil harus bersifat individual berdasarkan kebutuhan dan keinginannya sendiri. ${ }^{13}$

Distribusi responden yang terbanyak berdasarkan tenaga kesehatan yang melakukan pemeriksaan kehamilan yaitu sebanyak
25 responden (100\%) menjawab bidan dan dokter. Hal ini berarti tenaga kesehatan yang melakukan ANC di Puskesmas Ranomuut merupakan tenaga terlatih, karena bidan dan dokter memiliki kemampuan yang lebih mengenai pemeriksaan kehamilan/layanan antenatal sesuai profesi mereka.

Distribusi responden yang terbanyak berdasarkan pemeriksaan kehamilan yang biasa dilakukan yaitu sebanyak 25 responden (100\%) menjawab belum memenuhi kriteria 7T. Hal ini sejalan dengan penelitian yang dilakukan oleh Afif (2010) yang menunjukkan bahwa pelayanan ANC di Puskesmas Gombong I (Wero) belum dilakukan dengan ketentuan 7T, yaitu; timbang berat badan, ukur tekanan darah, ukur tinggi fundus uteri, pemberian imunisasi TT (Tetanus Toksoid) lengkap, pemberian tablet besi, tes terhadap penyakit menular seksual, dan temu wicara dalam rangka persiapan rujukan. ${ }^{14}$

Distribusi responden yang terbanyak berdasarkan jadwal kunjungan ANC menjawab satu kali pada trimester I dan II, dua kali pada trimester III yaitu sebanyak 25 responden (100\%). Kunjungan antenatal untuk pemantauan dan pengawasan kesejahteraan ibu dan anak minimal empat kali selama kehamilan dalam waktu; sampai dengan kehamilan trimester pertama $(<14$ minggu) satu kali kunjungan, dan kehamilan trimester kedua (14-28 minggu) satu kali kunjungan dan kehamilan trimester ketiga (28-36 minggu dan sesudah minggu ke-36) dua kali kunjungan. ${ }^{13}$

Distribusi responden yang terbanyak berdasarkan pemberian buku KIA menjawab YA sebanyak 25 responden (100\%). Salah satu tujuan Program Kesehatan Ibu dan Anak (KIA) yakni meningkatkan kemandirian keluarga dalam memelihara kesehatan ibu dan anak. Dalam keluarga, ibu dan anak merupakan kelompok yang paling rentan terhadap berbagai masalah kesehatan seperti kesakitan dan gangguan gizi yang seringkali berakhir dengan kecacatan atau kematian. Untuk mewujudkan kemandirian keluarga dalam memelihara kesehatan ibu dan anak maka salah satu upaya program yaitu meningkatkan pengetahuan dan keterampilan 
keluarga melalui penggunaan Buku Kesehatan Ibu dan Anak (Buku KIA). ${ }^{15}$

Distribusi responden yang terbanyak berdasarkan manfaat buku KIA menjawab berisi informasi yang berguna untuk kesehatan ibu dan anak serta untuk tenaga kesehatan sebanyak 25 responden (100\%). Kebijakan dan berbagai upaya pemerintah untuk menurunkan angka kematian ibu dan bayi, antara lain dengan kegiatan Gerakan Sayang Ibu (GSI), Strategi Making Pregnancy Safer dan pengadaan buku Kesehatan Ibu dan Anak (KIA). Buku KIA telah diperkenalkan sejak 1994 dengan bantuan Badan Kerjasama Internasional Jepang (JICA). Buku KIA diarahkan untuk meningkatkan pengetahuan dan pemahaman masyarakat tentang kesehatan ibu dan anak. Buku KIA selain sebagai catatan kesehatan ibu dan anak, alat monitor kesehatan dan alat komunikasi antara tenaga kesehatan dengan pasien. Diharapkan dapat meningkatkan partisipasi masyarakat dalam mengontrol kesehatan ibu. Penggunaan buku KIA merupakan salah satu strategi pemberdayaan masyarakat terutama keluarga untuk memelihara kesehatan dan mendapatkan pelayanan kesehatan yang berkualitas. Hal ini seyogyanya menjadi perhatian Pemerintah Kabupaten atau Kota. $^{15}$

\section{SIMPULAN}

Berdasarkan hasil penelitian dan pembahasan, maka dapat diambil kesimpulan bahwa tenaga kesehatan di Puskesmas Ranomuut telah mengetahui definisi antenatal care yaitu pemeriksaan dan pengawasan selama kehamilan dan tenaga kesehatan di Puskesmas Ranomuut telah mengetahui tujuan antenatal care yaitu agar dapat mengenali secara dini adanya ketidaknormalan atau komplikasi yang mungkin terjadi selama kehamilan. Pelaksanaan ANC berjalan sebagaimana mestinya dan pemeriksaan dilakukan oleh bidan dan dokter sedangkan jadwal pemeriksaannya yaitu satu kali pada trimester I dan II, dua kali pada trimester III. Pemantauan kehamilan oleh tenaga kesehatan sudah dilakukan sesuai prosedur dan tenaga kesehatan mengingatkan ibu hamil agar berkunjung tepat waktu sesuai jadwal kunjungan ANC serta memberikan buku KIA kepada ibu hamil.

Berdasarkan kesimpulan tersebut, maka dapat diberikan saran sebagai berikut:

1. Tenaga kesehatan dan instansi terkait (Puskesmas) diharapkan dapat memberikan pendidikan kesehatan (Komunikasi Informasi dan Edukasi, serta Promosi) dalam upaya meningkatkan motivasi masyarakat khususnya ibu hamil dalam melakukan pemeriksaan kehamilan secara teratur $\geq 4$ kali kunjungan pemeriksaan kehamilan (ANC).

2. Diharapkan menjadi bahan referensi bagi peneliti selanjutnya dan informasi bagi pihak yang berkepentingan untuk mengkaji dan meneliti lebih lanjut masalah yang sama di masa mendatang.

\section{DAFTAR PUSTAKA}

1. Sistem Kesehatan Nasional. Departemen Kesehatan RI. Jakarta; 2009. Available from:

http://www.depkes.go.id/downloads/SKN\% 20final.pdf Accesed on: 22 Oktober 2012.

2. Profil Kesehatan Provinsi Jawa Timur. Available from: http://dinkes.jatimprov.go.id. Accesed on 15 November 2012.

3. Kurniasih D. Faktor-Faktor yang Mempengaruhi Perilaku Terhadap Cakupan Kunjungan Antenatal Empat kali (K4) di Puskesmas Kecamatan Pasar Minggu [skripsi]. Jakarta: Program Studi S1 Kesehatan Masyarakat; 2010.

4. Badan Pusat Statistik. Survey Demografi dan Kesehatan Indonesia 2012 (SDKI12). Available from: http://www.bps.go.id/aboutus.php?info=70. Accessed on 22 Oktober 2012.

5. Kompas. Angka Kematian Ibu dan Anak. Available from: http://www.kompas.com. Accesed on 20 Oktober 2012.

6. Rondonuwu, Y. Angka Kematian Ibu di Sulut Tinggi. Editor. Araro R. Manado; Tribun Manado:2012.p.1.

7. Pendidikan Kesehatan dan Konseling Kebidanan. Dalam; Salmah, Rusmiati, Maryanah, Susanti N. N. Editor. Asuhan 
1080 Jurnal e-Biomedik (eBM), Volume 1, Nomor 2, Juli 2013, hlm. 1075-1080

Kebidanan Antenatal. Jakarta; Penerbit Buku Kedokteran:2005.p148.

8. The Jakarta Post. Indonesia Jauh dari Pencapaian Target Angka Kematian Ibu. Available from: http://www.jakartapost.com. Accesed on 23 Oktober 2012.

9. Sari AP, Maryati I, Solehati T. Hubungan Pengetahuan Ibu dan Resiko Tinggi Kehamilan dengan Kepatuhan Kunjungan Antenatal [skripsi]. Bandung: Fakultas Keperawatan Universitas Padjajaran;2011.

10. Saragih R. Gambaran Perilaku Masyarakat Tentang Pelayanan Puskesmas di Desa Sukaraya Kecamatan Pancur Batu Kabupaten Deli Serdang. Jurnal Darma Agung. 2010:59-68.

11. Astuti DA, Tyastuti S, Hastuti S. Gambaran Pelaksanaan Pelayanan Kebidanan Pada Penanganan Bayi Baru Lahir Oleh Bidan Delima Di Kabupaten Bantul Yogyakarta Tahun 2008. Jurnal Kebidanan dan Keperawatan. 2008;4:75-84.

12. Laili MH, Murti B, Murdani P. Hubungan Pengetahuan Dan Sikap Bidan Dengan Kemampuan Penerapan Standar Pelayanan Antenatal Pada Pelayanan Bidan Di
Wilayah Pandaan Kabupaten Pasuruan [tesis]. Surakarta: Program Pasca Sarjana Universitas Sebelas Maret;2012.

13. Situmeang R. Pengaruh Faktor Predisposisi, Pemungkin Dan Kebutuhan Terhadap Pemanfaatan Sarana Pelayanan Antenatal Oleh Ibu Hamil Di Kelurahan Pasir Bidang Kecamatan Sarudik Kabupaten Tapanuli Tengah Tahun 2010 [skripsi]. Medan: Fakultas Kesehatan Masyarakat Universitas Sumatra Utara; 2010.

14. Pramitasari A, Basirun, Suhartini. Evaluasi Pelaksanaan Pelayanan Antenatal Care (ANC) di Puskesmas Gombong I (Wero) [skripsi]. Kebumen: Program D III Kebidanan STIKES Muhammadiyah Gombong;2010.

15. Wahyuni S. Pengaruh Karakteristik Bidan Dan Organisasi Puskesmas Terhadap Pemanfaatan Buku Kia Sebagai Materi Penyuluhan Bagi Ibu Hamil Di Kabupaten Aceh Tengah [tesis]. Medan: Program Studi S2 Ilmu Kesehatan Masyarakat Fakultas Kesehatan Masyarakat Universitas Sumatera Utara; 2010. 